\title{
Recomendaciones de bioseguridad en consultorio, quirófano y pase de visita en ortopedia durante la pandemia de COVID-19
}

\author{
Recommendations for in-office bio-security, operating room and hospital \\ visit in orthopedics during the COVID-19 pandemic
}

\author{
Negrete-Corona J,*García-Pinto G, ${ }^{\ddagger}$ Diego-Ball D, ${ }^{\S}$ García-Dobarganes Barlow FE, \\ Delgado-Cedillo E," Cobaleda-Aristizabal AF,** Aguirre-Rodríguez VH,

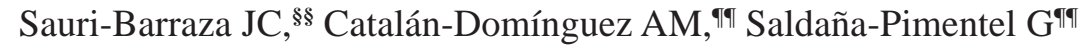 \\ Colegio Mexicano de Ortopedia y Traumatología, A. C.
}

\section{Introducción}

La pandemia generada por el virus SARS-CoV-2 (y conocida como COVID-19 a la enfermedad causada por este coronavirus) ha generado un severo impacto no sólo en la salud y la economía, sino también dentro del ámbito social y personal, lo que ha ocasionado que se busquen diversas y múltiples formas de enfrentar el problema, pues, al día de hoy, aún no se tiene una vacuna o un tratamiento ideal para dicho problema. Por esta razón, lo que podemos hacer como comunidad médica es prepararnos, capacitarnos y ayudarnos, generando medidas de protección y recomendaciones para un mejor control de la cadena de transmisión de la enfermedad.

Frente a esta pandemia, evidentemente, el personal de salud se ha convertido en la primera línea de riesgo, pues es el encargado de examinar y tratar a pacientes en diferentes estadios de la enfermedad, y esto hace que puedan llevar el virus a su familia y a la comunidad, por lo que debemos insistir en las medidas de protección estrictas para el personal de salud.
El Colegio Mexicano de Ortopedia y Traumatología, como organismo que agrupa a los ortopedistas a nivel nacional, quiere colaborar emitiendo una serie de medidas y recomendaciones de protección personal durante el acto médico: en consultorio, urgencias, quirófano y en cirugía programada que sean prácticas y accesibles, tomando en consideración que estamos en constantes cambios respecto al tema. Asimismo, se busca complementarlas con un adenda de recomendaciones jurídicas de protección del médico, sin olvidarnos de los derechos del paciente y tampoco de los derechos del médico.

\section{Epidemiología}

El 31 de diciembre de 2019, China informó sobre un grupo de casos de neumonía con etiología desconocida. ${ }^{1,2}$ El 30 de enero de 2020, el Director General de la Organización Mundial de la Salud (OMS) declaró que el brote era una emergencia de salud pública de importancia internacional (ESPII). El 28 de febrero se reportaron en México tres casos

*Presidente del Colegio Mexicano de Ortopedia y Traumatología A. C. Hospital Ángeles Metropolitano. Ciudad de México, México.

${ }^{\ddagger}$ Vicepresidente del Colegio Mexicano de Ortopedia y Traumatología A. C. Hospital Central Militar. Ciudad de México, México.

§ I Secretario Propietario del Colegio Mexicano de Ortopedia y Traumatología A. C. Centro Médico ABC. Ciudad de México, México.

" II Secretario Propietario del Colegio Mexicano de Ortopedia y Traumatología A. C. Hospital Ángeles Querétaro. Santiago de Querétaro, Qro.

" Presidente del LXV Congreso Nacional de Ortopedia 2020, Instituto Nacional de Rehabilitación «Luis Guillermo Ibarra Ibarra». Ciudad de México, México.

** Titular del Capítulo de Especialización en Artroscopía. Ortopedia del Deporte y Cartílago, Hospital Ángeles Metropolitano. Ciudad de México, México.

\# Titular del Capítulo de Especialización en Cadera y Rodilla. Hospital Ángeles Pedregal. Ciudad de México, México.

${ }_{\S}^{\S}$ Miembro Titular del Colegio Mexicano de Ortopedia y Traumatología A. C. Centro Médico ABC. Ciudad de México, México.

१ึ Abogado, Consultoría Especializada en Riesgos Profesionales; participación especial.

Dirección para correspondencia:

Colegio Mexicano de Ortopedia y Traumatología, A. C.

Montecito Núm. 38, piso 25, oficinas 23-27, Col. Nápoles, C. P. 03810, Alcaldía Benito Juárez, CDMX. Teléfono: $559000-2790$ al 94

Dr. Jorge Negrete-Corona

E-mail: negretdoc@hotmail.com

Citar como: Negrete-Corona J, García-Pinto G, Diego-Ball D, García-Dobarganes Barlow FE, Delgado-Cedillo E, Cobaleda-Aristizabal AF, et al. Recomendaciones de bioseguridad en consultorio, quirófano y pase de visita en ortopedia durante la pandemia de COVID-19. Acta Ortop Mex. 2020; 34(3): 158-166. https://dx.doi.org/10.35366/97068

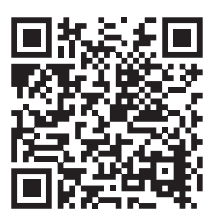


importados de Italia y se documentó un contacto directo durante una convención en Bérgamo, Italia; a partir de esta fecha, se estableció un plan «epidemiológico» en México, cuyo objetivo es reducir la cantidad de casos de infecciones, retrasar el avance de la enfermedad y reducir el número de casos de hospitalización. ${ }^{3}$

Hay tres escenarios delineados para atender la situación. El primero es el escenario inicial: pequeños brotes aislados (decenas de casos) reportados desde el 28 de febrero hasta el 23 de marzo de 2020. El segundo es el escenario de propagación comunitaria: donde el virus se dispersó en una zona localizada (cientos de casos), declarándose la fase 2: del 23 de marzo al 21 de abril. Finalmente, el último es el escenario propagación amplia: donde el virus se dispersó por todo el país (miles de casos), declarándose la fase 3: del 21 de abril hasta la fecha.

La pandemia por COVID-19 nos pone ante un escenario sin precedente y con un nuevo actor en México y el mundo: el virus SARS-CoV-2, teniendo diferentes elementos que se deben de tomar muy en cuenta para mantener nuestra práctica clínica y quirúrgica, tanto para nuestros pacientes como para el equipo de colaboradores, e incluso, para la seguridad de nosotros mismos.

\section{Recomendaciones para el consultorio del ortopedista}

Para disminuir la probabilidad de contagio en el consultorio en donde se encuentran en riesgo secretarias, enfermeras, médicos, pacientes y acompañantes, se sugieren las siguientes recomendaciones:

- Mantenerse informado del avance día a día a través de la Secretaría de Salud, Federal o Estatal, de sus colegios de especialidad, páginas autorizadas de Internet, para protegerse a usted mismo, su personal del consultorio y a sus pacientes.

- Se debe asumir que todo paciente ortopédico tiene coronavirus, a pesar de que se vea asintomático, por lo que, desde la fase dos de una epidemia, deberá hacer una selección de cuáles pacientes requieren atención inmediata o mediata y cuáles se pueden posponer. ${ }^{4,5}$

Pacientes con padecimientos que no son urgencia:

- Se sugiere asesorar al paciente por teleconferencia en una plataforma digital y valorar durante la reunión por teleconferencia si el paciente requiere de atención presencial.

- De ser posible, hay que reprogramar las citas, especialmente en pacientes mayores de 65 años o con comorbilidades.

Pacientes que tienen una «relativa urgencia» y que requieren ser revisados en el consultorio:

I. Antes que nada, es necesario considerar los siguientes aspectos al realizar las citas de los pacientes:
- Espaciar las consultas y agendarlas de tal manera que exista el mínimo de personas en la sala de espera.

— En la manera que sea posible, el paciente debe venir solo o con un acompañante; está prohibido hacerse acompañar de grupos vulnerables (tercera edad, diabéticos, hipertensos, etcétera).

- Invitar a que todos los pacientes y sus acompañantes entren con cubrebocas. En caso de no traerlo, hay que proporcionárselo y exigir el lavado de manos en el baño de la sala de espera, o usar gel antibacteriano.

— Es mandatorio no ver pacientes con síntomas que pudieran corresponder a la enfermedad por coronavirus. Sería oportuno verlos en Urgencias de un hospital que reciba pacientes con sintomatología de COVID-19, y valorarlo con el equipo de protección personal (EPP) adecuado.

- Solicitar el pago de honorarios de consulta de forma anticipada por transferencia electrónica. Evitar el uso de efectivo.

II. Consideraciones para el personal del consultorio:

- Tanto el personal administrativo como las enfermeras y el personal de limpieza deberán usar permanentemente cubrebocas y caretas. En caso de que los primeros sean de tela o de los llamados «de quirófano», es necesario cambiarlos cuando menos cada seis horas.

- Prohibido saludar de mano, y mucho menos de beso o abrazo.

III. Consideraciones para el espacio físico del consultorio:

- A la entrada, de preferencia, tener un tapete desinfectante o charola con agua y cloro para la sanitización del calzado.

- Contar con gel antibacteriano en el área de la recepción.

— Favorecer la ventilación e iluminación natural del consultorio.

- Al finalizar la consulta de cada paciente, las áreas de contacto del paciente deberán ser limpiadas con papel empapado en agua con cloro o usar toallas sanitizantes.

IV. Consideraciones para el médico:

— Estar presente en el consultorio el tiempo indispensable.

— Prohibido usar corbata.

— Uso irrestricto de cubrebocas, de preferencia N95 y protección ocular (careta o lentes de protección).

- Siempre usar guantes de látex para la exploración, y cambiarlos con cada paciente. 
— Lavarse las manos antes y después de revisar a cada paciente, incluso si se usan guantes.

\section{Consideraciones para la cirugía}

Para valorar si el paciente requiere ser intervenido quirúrgicamente durante la pandemia de COVID-19, es necesario analizar aspectos del paciente, de qué patología se trata y qué tipo de cirugía es la que se requiere, de modo que se determine si vale la pena someter a un paciente a un procedimiento, sabiendo que hay antecedentes de que pacientes operados tienen mayor riesgo de contagiarse de COVID-19 y requieren ventilación mecánica. ${ }^{6,7}$

\section{Consideraciones del paciente:}

- Identificar si tiene COVID-19. Todos los pacientes deben considerarse como sospechosos hasta que se demuestre lo contrario. ${ }^{8}$ Se recomienda realizar una prueba PCR para COVID-19 y una Tomografía Axial Computarizada de tórax ${ }^{9}$ a todo paciente asintomático antes de cirugía; si no es posible hacer eso, habrá que operar con EPP. ${ }^{10}$

- Basado en la valoración prequirúrgica del anestesiólogo, utilizar la clasificación de ASA para valorar el estado general del paciente. A saber: ${ }^{8}$

1. Riesgo bajo: ASA I y II. Pacientes sanos.

2. Riesgo alto: ASA III y IV. Mayores de 60 años y/o con comorbilidades.

3. Riesgo severo: ASA V y VI. Operar sólo si la patología es la causa de riesgo de vida.

II. Severidad y urgencia de la patología. Adaptamos la clasificación propuesta por la American Academy of Orthopedic Surgeons (AAOS) ${ }^{11}$ y por de la Asociación Mexicana de Cirugía de Columna (AMCICO) ${ }^{8}$ para nuestras necesidades:

- Emergencia: requiere cirugía en las primeras ocho horas:

1. Fracturas (Fx) expuestas

2. Fracturas con compromiso vascular, visceral, orgánico o neurológico (síndrome compartimental)

3. Luxaciones

4. Amputación traumática

5. Artritis séptica

6. Fracturas de columna con lesión medular incompleta

7. Síndrome de cauda equina

- Urgencia: requiere cirugía en las primeras 48 horas:

1. Fractura desplazada (huesos largos, cadera, fractura articular/epifisiolistesis, inestabilidad pélvica o columna; fractura patológica y/o riesgo de lesión vascular o neurológica)

2. Lesión tendinosa total o severa, múltiple o asociada con lesión de partes blandas
3. Reducción cerrada de fracturas

4. Dolor incapacitante, sin mejoría con tratamiento conservador (TxCo)

5. Déficit motor (columna), agudo o progresivo, independientemente de la etiología

6. Absceso epidural en columna

7. Es difícil encasillar todos los escenarios de una patología. Individualizar cada caso y valorar si el paciente requiere un tratamiento quirúrgico inmediato o se puede posponer

- Semielectiva: requiere cirugía en los primeros 7 a 14 días:

1. Fractura poco desplazada o de huesos cortos que no entran en urgencia

2. Lesiones cartilaginosas traumáticas agudas

3. Biopsia en lesiones óseas con sospecha de malignidad

4. Lesiones que causan bloqueo articular o inestabilidad, sin mejoría con tratamiento conservador (TxCo)

5. Infección sin mejoría con TxCo

- Electiva: se puede realizar de seis a ocho semanas (valorar condiciones locales y hospitalarias de contagio).

Todas las demás cirugías, independientemente de su etiología, se deberán posponer

III. Tipo de cirugía. Valorar la agresividad de la cirugía: ${ }^{8}$

- Cirugía tipo 1. Puede hacerse ambulatoria (ideal) o de corta estancia ( $<48$ horas). Paciente estable es de bajo riesgo.

—Cirugía tipo 2. Mayor a 48 horas de hospitalización. Paciente estable es de riesgo intermedio.

- Cirugía tipo 3. Requiere de transfusiones o Unidad de Cuidados Intensivos (UCI). Paciente inestable es de alto riesgo.

IV. Recomendaciones pre, intra y postoperatorias (paciente sospechoso o con COVID-19) ${ }^{12}$

\section{— Recomendaciones preoperatorias:}

- Valorar la urgencia, el paciente, la cirugía, los recursos necesarios y dónde se va a realizar la cirugía.

- Todo paciente no intubado debe usar cubrebocas (facilitado por el hospital).

- Todo el personal en contacto con el paciente debe de usar EPP: mascarilla N95, gafas de protección, botas, bata y doble guante (facilitado por el hospital).

- El personal deberá vestirse en la antesala o quirófano. La secuencia para vestirse es la siguiente:

1. Higiene de manos

2. Botas

3. Primer guante 

4. Bata
5. Mascarilla
6. Gorro
7. Gafas de protección
8. Segundo guante

— Consideraciones anestésico-quirúrgicas:

- De preferencia, realizar anestesia regional o local. Intubación en el quirófano.

- Personal no involucrado en intubación, incluyendo al ortopedista, deben estar por lo menos a 2 metros, o fuera de quirófano durante el proceso completo.

— Recomendaciones intraoperatorias:

- La ventilación del quirófano debe mantenerse en presión negativa o neutra si está disponible.

- Utilizar material desechable de preferencia.

- Sólo debe permanecer el equipo quirúrgico y personal indispensable en la sala.

- La cirugía deberá ser realizada por el cirujano más experimentado, cuya técnica resulte más familiar y que permita la recuperación más rápida y de menor estancia hospitalaria.

- Reportar contacto directo con secreciones al usar instrumentos quirúrgicos.

- Evitar o minimizar brocado, rimado, fresado, lavado pulsátil y humo de coagulación.

— Postoperatoria

- Desvestirse en antesala (espacio designado por el hospital para vestirse y desvestirse con EPP, puede ser fuera o dentro de quirófano). La secuencia a seguir es la siguiente:

1. Primer guante

2. Higiene de manos

3. Mascarilla

4. Higiene de manos

5. Retiro de bata y segundo guante

6. Higiene de manos

7. Gafas de protección

8. Botas

- El paciente debe extubarse en quirófano si es posible (sólo permanecerá el equipo de anestesia en la sala).

\section{Protección hospitalaria}

Se deben implementar medidas de protección para el personal de salud, médicos, enfermeras, camilleros, intendencia, etc., para evitar que sean contagiados. ${ }^{10}$
Paciente sin COVID-19 y patología traumática: ${ }^{12}$

1. Pacientes hospitalizados traumáticos: tienen por definición un sistema inmune deficiente. Ellos deberá utilizar máscaras faciales o cubrebocas (facilitadas por el hospital ${ }^{13}$ para su protección personal, evitar toda posibilidad de contagio a su paciente vecino y protección al personal de salud del hospital.

2. Solo un familiar por paciente: se debe tener un registro de éste por si hubiera una eventual exposición al virus y deberá utilizar cubrebocas y realizar higiene de manos constante. Su permanencia, de preferencia, debe ser breve y sin visitas médicas.

3. Tiempo de espera quirúrgico: deberá ser lo antes posible de acuerdo con la patología traumática del paciente, y si sus condiciones metabólicas o cutáneas lo permiten. ${ }^{13}$

4. El pase de visita debe ser sólo por el médico tratante para evitar aglomeraciones y con todo el equipo EPP (cubrebocas idealmente N95, ${ }^{13,14,15}$ máscara facial, guantes, etcétera).

5. Se recomienda uso de cubrebocas (N95) $)^{13,14,15}$ a todos los médicos ortopedistas por ser el de mayor protección.

6. Se deberá realizar pruebas de COVID-19 a todo paciente hospitalizado y que será sometido a una cirugía; de esta manera, hay más información para protección del personal de salud y del paciente.

7. Posterior a la cirugía, es necesario realizar curaciones de la herida quirúrgica. El médico tratante debe utilizar todo el equipo de $\mathrm{EPP}^{15} \mathrm{y}$ lavado posterior de manos.

8. Alta a la brevedad posible.

Pacientes con COVID-19 y patología traumática:

1. De preferencia, el traslado será a hospital COVID. Si no es posible, entonces pasará el paciente aislado en el área especial de COVID del hospital designado.

2. Si se requieren puntas nasales, es necesario utilizar cubrebocas para la protección del personal.

3. Acelerar el procedimiento quirúrgico si sus condiciones generales lo permiten. ${ }^{13}$

4. El pase de visita de los pacientes hospitalizados deberá ser con equipo especial (doble gorro, doble guante, cubrebocas N95, ${ }^{13}$ gafas, máscara facial y ropa especial aislante). ${ }^{14}$

5. Al salir de esta sala, el médico deberá bañarse y cambiarse de ropa quirúrgica.

6. El transporte hacia la sala de quirófanos deberá ser notificado para que no haya personas en la ruta. En este traslado participará el equipo de seguridad. El personal de enfermería que lo llevará a cabo, deberá estar protegido en todo momento con todo el equipo de $\mathrm{EPP}^{15}$ y deberán planificar y coordinar este transporte para evitar pérdidas de tiempo.

7. Posterior a la cirugía, es necesario trasladarlo a un hospital COVID para su manejo integral. De no ser posible, pasar a sala de aislado; todo el personal debe contar con el EPP ${ }^{15}$ 
completo y valorar el alta del paciente a la brevedad posible, siempre y cuando sus condiciones generales lo permitan.

Recomendaciones legales

Consideraciones legales para los miembros del Colegio Mexicano de Ortopedia y Traumatología, A.C. ("CMO") para una adecuada relación MÉDICOPACIENTE, sea durante la pandemia producida por el virus SARS-CoV-2 como para la prevención de demandas, denuncias $y / 0$ cualquier procedimiento en contra del personal de la salud a mediano y largo plazo, bajo un contexto de respeto a los derechos humanos de todos los miembros de la sociedad y atendiendo, hoy más que nunca, a los principios que rigen la práctica médica.

Primero.- La actuación del médico puede llegar a ser calificada por la autoridad judicial (civil-penal) y/o administrativa nacional como lesiva para el paciente, dentro de un contexto casuístico:

\section{a) Vía penal. Conducta culposa.}

El actuar con culpa significa generar un hecho lesivo o dañino a un bien jurídicamente tutelado, como puede serlo la salud y la vida de una persona, el cual no deseábamos producir (sin dolo), pero que, efectivamente, lo causamos, sea por no prever esa posibilidad, no atender las circunstancias particulares, o bien que, incluso previéndolo, hubo una confianza excesiva de que no se produciría ese daño: homicidio, lesiones, responsabilidad profesional, riesgo de contagio y/o los que resulten.

Para evitarlo, recomendamos:

- No efectuar intervenciones quirúrgicas electivas (desde el punto de vista de la traumatología y ortopedia) a los pacientes que se encuentren en grupos de mayor vulnerabilidad: sesenta años en adelante y/o con factores de riesgo alto para contraer la enfermedad COVID-19 (y/o con comorbilidades conocidas a la fecha), ya que los resultados indeseados les pueden ser atribuidos penalmente; además el tratamiento pudiera haber sido conservador y esperar la evolución de la pandemia para situarnos en mejores condiciones temporales y científicas.

- Excepcionalmente, el personal médico podría llegar a recibir una imputación más grave: pretendiendo encuadrar su conducta en un dolo eventual. Esto es, cuando, conocedor de que un paciente tiene todos o varios los factores de alto riesgo y comorbilidades (ubicado en las circunstancias del sistema de salud público o privado), aun así propone y realiza un procedimiento electivo en plena pandemia, pudiendo significar que el médico es consciente del peligro de la producción del resultado dañoso, pero continúa adelante sin importar si se realiza o no, aceptando y asumiendo con ello el resultado al ser consciente del peligro que ha creado.

\section{b) Vía civil. La responsabilidad civil objetiva y subjetiva} (daño moral).

La acción civil tiene fines preponderantemente económicos (además de declaratorios sobre la negligencia médica). Radica particularmente el daño moral en cuestiones subjetivas y bienes jurídicos intangibles: el dolor de perder un padre, una madre o un hijo, y las secuelas emocionales que de ello se desprenden: la depresión por perder una función orgánica o ver truncado el plan de vida en determinado rubro por las secuelas del tratamiento.

Una vez comprobado que el actuar médico no siguió las reglas de la buena práctica y sus principios y, por ende, existe nexo causal con el resultado lesivo, se cuantificará el daño a través de diversos medios de prueba como periciales, siquiátricas, sicológicas, contables y de trabajo social, particularmente aquéllas que pueden acarrear sentencias condenatorias muy cuantiosas.

c) Vía administrativa. Órganos internos de control (contralorías) y comisiones de conciliación y arbitraje médico.

Pueden ser iniciadas quejas ante las comisiones estatales o nacionales de conciliación y arbitraje médico en busca de una solución pacífica a las controversias; con ellas, sin duda, amén de las bondades para las partes, como son la conciliación y la posibilidad de someterse o no a un procedimiento arbitral, no implica que carezcamos de la presión de estar bajo la revisión vigilante de una autoridad experta en temas médico-legales.

\section{Cuestión particular en su atención \\ merece el siguiente caso:}

Como servidores públicos, durante la pandemia, podemos ser investigados o iniciarse en nuestra contra procedimientos por responsabilidad administrativa, sea de oficio o a petición de parte.

Se puede incurrir en faltas graves o no graves $\mathrm{y}$, dependiendo de ello, podrán tener sanciones, las cuales van desde una amonestación pública o privada, suspensión del empleo, cargo o comisión sin goce de sueldo, destitución del cargo e inhabilitación para desempeñar el servicio público, sanción económica e, incluso, dar vista al Ministerio Público para que se investiguen hechos con apariencia de delito.

El personal de la salud debe efectivamente cumplir con su trabajo, siempre y cuando en sí mismo:

1. No implique un daño directo a su integridad, salud o vida, o una violación directa a sus derechos y bienes jurídicamente tutelados. 
2. No implique que el mandato realice un actuar indebido e ilegal frente a terceros.

Por lo anterior, para el caso del personal remitido al área COVID o que tenga contacto y/o brinde atención a este tipo de pacientes, recomendamos el cumplimiento de sus funciones alternas, siempre que sean:

- De carácter temporal justificado y el personal de la salud no se encuentre en la población de alto riesgo por edad o comorbilidades.

- No impliquen en sí misma la realización de actos de especialidad que desconozcan y para lo cual requieran cedula de especialidad y/o certificación necesaria del Consejo correspondiente regulado por CONACEM, pero sí deberán ejercer todas aquéllas que por sus conocimientos como médicos generales (o especialistas) deban tener según los planes y programas de estudio, concatenado con la capacitación y adiestramiento recibido oficialmente para ejercer la medicina.

- El personal reasignado deberá ejercer bajo la titularidad, guía y vigilancia plena de un especialista y sólo ejercer las actividades que deban y puedan realizar de manera efectiva. De lo contrario, invaden un campo de especialidad desconocido, para el cual tienen impericia en perjuicio de su propia salud y la de terceros (bajo riesgo de incurrir en usurpación de profesión y negligencia de origen).

- Deberán solicitar que el titular del área reasignada firme autógrafamente con nombre completo y número de cédula profesional las notas de evolución y órdenes médicas, erigiéndose así como médico tratante de los pacientes. De este modo, pueden ustedes colaborar a petición del titular en la elaboración de la nota, la cual deberá ser revisada y aprobada por el médico tratante bajo los requisitos mencionados.

- No ingresar a áreas de riesgo y/o alto riesgo sin la protección necesaria y adecuada para cada caso según corresponda. Se debe hacer del conocimiento de la autoridad hospitalaria por escrito de manera inmediata de tales carencias y no ausentarse de ninguna manera de sus centros de trabajo (colocándose en un área segura), ya que no pueden ser obligados a trabajar sin el material necesario y adecuado, pues ello significaría situarlos en un riesgo de contagio (delito), con violación a su derecho humano a la salud previsto en el Artículo 4o. Constitucional. Si tienen el material necesario y adecuado, no pueden negarse a laborar.

- Toda falla (material, insumos, limpieza y/o diversa) atribuible a la institución (o sus encargados) para el desempeño idóneo de su trabajo debe hacerla del conocimiento de la dirección y/o quien resulte competente en el organigrama interno, por escrito, de manera respetuosa y conservar los acuses de recepción originales.

- Conservar los oficios generales o particulares donde se les ordena la reasignación o realización de funciones alternas. Para el caso de ser indicación verbal, deberán solicitar por escrito que se les entregue del mismo modo tal reasignación de funciones.

Segundo.- En caso de tratarse de procedimientos necesarios, deben tomarse en cuenta las siguientes recomendaciones:

- Propuesta de estandarización de la necesidad.

- De haber la posibilidad de elección de hospital o unidad hospitalaria, subsumirse a los criterios propuestos.

- Orden de estudios de control, que en condiciones normales no serían necesarios.

Tercero.- Firma del Adenda de consentimiento informado que se ha proporcionado a los miembros del CMO para su uso inmediato, el cual deberá requerir con independencia del aquélla que utilicen de manera cotidiana en su práctica médica particular e institucional (Anexo A).

Cuarto.- La consulta médica vía remota (What'sApp, Skype, Zoom, videollamada, y/o otro similar o análogo) no es legal a través redes sociales particulares y dispositivos privados.

Cualquier tipo de asesoría para la salud que brinden a distancia no pueden ni deben denominarla como consulta médica y/o atención médica; en su caso, es únicamente una herramienta de apoyo y orientación para la salud. Necesariamente la atención médica debe ser presencial con todos los requisitos de ley, para emitir un diagnóstico certero y propuestas de tratamiento.

Quinto.- La atención de consulta externa debe tomar en cuenta las medidas de prevención y protección emitidas por el Gobierno Federal.

Sexto.- Tratándose de pacientes con seguro de gastos médicos, y sin que ello sea de nuestro interés primordial, recomendarles verificar con su agente o persona encargada si su seguro cubre o no la enfermedad COVID-19 para que, como una extensión del derecho del paciente a saber, no lo enfrentemos a una situación económica-patrimonial complicada sin su conocimiento.

Bibliografía

1. Lu R, Zhao X, Li J, et al. Genomic characterization and epidemiology of 2019 novel coronavirus: implications for virus origins and receptor binding. Lancet. 2020; 395(10224): 565-74.

2. Zhou P, Yang XL, Wang XG, et al. Discovery of a novel coronavirus associated with the recent pneumonia outbreak in humans and its potential bat origin. bioRxiv. 2020 [published online ahead of print January 2020].

3. Gobierno de México. Todo sobre el COVID-19. 2020 [portal web]. Recuperado de: https://coronavirus.gob.mx/

4. TDC Group. COVID-19 and patient safety in the medical office. Recuperado de: https://www.thedoctors.com/articles/2019-novelcoronavirus-and-patient-safety-in-the-medical-office/

5. Wu Z, McGoogan JM. Characteristics of and important lessons from the coronavirus disease 2019 (COVID-19) outbreak in China: 
Summary of a Report of 72314 Cases From the Chinese Center for Disease Control and Prevention. JAMA. 2020; 323(13): 1239-42.

6. Siddiqui S. CMS Adult Elective Surgery and Procedures Recommendations: Limit all Non-essential Planned Surgeries and Procedures, Including Dental, until Further Notice; 2020. Available in: https://www.cms.gov/files/document/31820-cms-adult-electivesurgery-and-procedures-recommendations.pdf.

7. American College of Surgeons. ACS Recommendations for management of elective surgical procedures [27/03/2020]. Recuperado de: https://www.facs.org/covid-19/clinical-guidance/ elective-surgery

8. Sauri-Barraza JC, Callejas-Ponce E, García-Ramos CL, et al. Recomendaciones para la toma de decisiones para realizar una cirugía de columna durante la pandemia de COVID-19 [04/2020]. Recuperado de: https://amcico.com.mx/amcico/index.php

9. Mouton C, Hirschmann MT, Ollivier M, Seil R, Menetrey J. COVID-19: ESSKA guidelines and recommendations for resuming elective surgery. J Exp Orthop. 2020; 7(1): 28.

10. Baldock TE, Bolam SM, Gao R, Zhu MF, Rosenfeldt MPJ, Young $\mathrm{SW}$, et al. Infection prevention measures for orthopaedic departments during the COVID-2019 pandemic: a review of current evidence. Bone \& Joint Open. 2020; 1(4): 74-79.
11. Guy DK, Bosco JA, Savoie FH. AAOS Guidelines on Elective Surgery during the COVID-19 Pandemic: March 31. COVID-19: Member Resource Center. Disponible en: https://www.aaos.org/globalassets/ about/covid-19/aaos-guidelines-on-electivesurge.pdf

12. Prada C, Chang Y, Poolman R, Johal H, Bhandari M. Best practices for surgeons: COVID-19 evidence-based scoping review. A unifying report of global recommendations. OrthoEvidence [22/04/2020]. Recuperado de: https://myoe.blob.core.windows.net/docs/OEBest-Practices-for-Surgeons-COVID-19-Evidence-Based-ScopingReview.pdf

13. Guo X, Wang J, Hu D, Wu L, Gu L, Wang Y, et al. Survey of COVID-19 disease among orthopaedic surgeons in Wuhan, people's Republic of China. J Bone Joint Surg Am. 2020; 102(10): 847-854.

14. Liang ZC, Chong MSY, Sim MA, Lim JL, Castañeda P, Green DW, et al. Surgical considerations in patients with COVID-19: what orthopaedic surgeons should know. J Bone Joint Surg Am. 2020; 102(11): e50. doi: 10.2106/JBJS.20.00513.

15. Hirschmann MT, Hart A, Henckel J, Sadoghi P, Seil R, Mouton C. COVID-19 coronavirus: recommended personal protective equipment for the orthopaedic and trauma surgeon. Knee Surg Sports Traumatol Arthrosc. 2020; 28(6): 1690-8. doi: 10.1007/s00167-02006022-4. 
Adenda de consentimiento informado que se incluye para la propuesta de prestación de servicios durante la contingencia epidemiológica motivada por la enfermedad ocasionada por el virus SARS-CoV-2 (COVID-19).

Con fundamento en la Constitución Política de los Estados Unidos Mexicanos, la Ley General de Salud, el Reglamento de la Ley General de Salud en Materia de Servicios de Atención Médica y la Norma Oficial Mexicana NOM-004-SSA3-2012 Del Expediente Clínico, Acuerdos del Consejo de Salubridad General publicados en el Diario Oficial de la Federación relativo al virus SARS-CoV-2 (COVID-19), y de manera general en cumplimento al derecho vigente y positivo de aplicación obligatoria en los Estados Unidos Mexicanos, se emite el siguiente:

Yo , mediante el presente hago constar que:

1. Es mi libre voluntad, sin que medie coacción de persona alguna, solicitar y recibir atención médica de urgencia o de cualquier otra índole durante la actual contingencia sanitaria por la enfermedad ocasionada por el virus SARS-CoV-2 (COVID-19).

2. Entiendo y acepto las medidas preventivas para evitar la propagación del virus SARSCoV-2 (COVID-19) y su contagio en este lugar de atención médica.

3. Se me explicó en lenguaje coloquial, claro y sencillo y, por tanto, entiendo bien que la enfermedad popularmente conocida como COVID-19 (virus SARS-CoV-2 - COVID-19) es causada por el virus coronavirus SARS-CoV-2 que tarda en manifestar síntomas, lo que se denomina período de incubación de la enfermedad. La mayoría de las estimaciones respecto al período de incubación del virus SARS-2-CoV-2 (COVID-19), que es el tiempo largo o prolongado que transcurre entre la infección por el virus y la aparición de los síntomas, en ese lapso, los contagiados son portadores de ese virus y suelen ser altamente contagiantes, aun sin mostrar síntomas, por lo que es imposible determinar oportunamente quién es portador o no, dada la demora en la obtención de resultados con pruebas confiables.

4. Estoy consciente de que no hay ninguna vacuna ni medicamento antiviral específico para prevenir o tratar el virus SARS-CoV-2 (COVID-19). Sin embargo, los contagiados deben recibir atención de salud (medidas de apoyo) para aliviar los síntomas. Las personas que presentan casos graves de la enfermedad deben ser hospitalizadas.

5. Estoy al tanto que la contingencia sanitaria en el país se encuentra en la Fase 3 denominada «de epidemia», la cual es la más crítica y en ésta es donde se acumulan un gran número de casos de contagios y de hospitalizaciones.

6. Fui informado que las formas más eficaces de protegerse a uno mismo y a los demás frente al virus SARS-CoV-2 (COVID-19) son: lavarse las manos con frecuencia, cubrirse la boca con el codo o con un pañuelo de papel al toser, mantener una distancia de, al menos, 1 metro con las personas que tosen o estornudan y el resguardo domiciliario.

Conforme a lo anterior, ENTIENDO Y ACEPTO que, aun con las precauciones y medidas preventivas, siempre existe riesgo de contagio, debido a la frecuencia de visitas a los pacientes, las características del virus y las condiciones generadas por los procedimientos y/o acciones médicas, por lo que el hecho de estar o permanecer en un consultorio u hospital podría ocasionar un contagio que eventualmente pudiera dar lugar a un aislamiento forzoso u otras medidas emitidas por la autoridad de salud.

Asimismo, me han informado y por ello estoy consciente que bajo la pandemia actual hay pautas generales, siendo las principales mantener distancia social y personal; medidas de higiene que se hacen del conocimiento del público en general, como hecho notorio, en campañas nacionales y locales de salud, así como el resguardo domiciliario, por lo tanto, no se recomienda la atención y/o procedimientos médico-quirúrgicos que no tengan carácter urgente. 
No obstante, yo confirmo que estoy buscando tratamiento o atención para una afección consistente en (denominación completa) para la que se me informaron las diversas alternativas y criterios para mi mayor seguridad, pero que no garantizan inmunidad o invulnerabilidad ante el virus SARS-CoV-2 (COVID- 19).

En caso de que yo requiera hospitalización, me sujetaré a las disposiciones que señalen en ese momento los protocolos de visitas señalados por la Secretaría de Salud (Federal y/o Local) durante la presente contingencia sanitaria. También doy mi autorización para recabar los datos personales necesarios (incluidos datos sensibles) a efecto de reportar de inmediato a la Secretaría de Salud si durante mi hospitalización me convierto en un caso confirmado o sospechoso por el virus SARS-CoV-2 (COVID-19), dando mi consentimiento para que toda la información o datos que yo proporcione, ya sea personal y/o sensible, pueda ser utilizada y/o dada a conocer a las autoridades de salud del país, la cual servirá para orientar las medidas de contención de la actual pandemia.

En caso de mi fallecimiento por enfermedad ocasionada por el virus SARS-CoV-2 (COVID-19) (ya sea confirmado o sospechoso), mi cuerpo será tratado como lo señala el Protocolo de Manejo de Cadáveres que determine la Secretaría de Salud (Federal y/o Local) durante esta contingencia sanitaria.

Bajo protesta de decir verdad, manifiesto que no estoy presentando ninguno de los síntomas compatibles con el virus SARS-CoV-2 (COVID-19) que se enumeran a continuación ni tampoco que he estado en contacto con pacientes confirmados o con sospecha del virus SARS-CoV-2 (COVID-19) en los últimos 15 (quince) días:
a) Dolor de garganta
b) Tos seca
(No)
c) Falta de aliento
d) Cansancio
e) Escurrimiento nasal
f) Fiebre
g) Dolor generalizado
h) Diarrea y/o problemas gastrointestinales
(No)

Paciente/Responsable

Nombre, Firma y Cédula Profesional
Médico tratante

Nombre, Firma y Cédula Profesional

\section{Testigo (nombre y firma) \\ Testigo (nombre y firma)}

Fecha (día/mes/año):

Hora:

Ciudad: 